\title{
CÓMO VIVIR JUNTOS. ARTES DEL ESPACIO Y AFECTIVIDAD EN EL OTRO DÍA, DE IGNACIO AGÜERO
}

\author{
Irene Depetris Chauvin*
}

\begin{abstract}
Resumo: Como dramas móviles del espacio, ciertas películas no sólo abordan problemáticas ya tratadas por la arquitectura y el urbanismo como campos de saber especificos, sino que exploran, desde el discurso audiovisual, nuevas formas de pensar los "pasajes" entre espacios cerrados y abiertos, visibles e invisibles, públicos y privados. Desde un abordaje atento a los cruces entre teorías del espacio y afectividad, este artículo analiza los modos en que el documental El otro día (2012), del chileno Ignacio Agüero, redefine los vínculos entre los modos de pensamiento espacial de la arquitectura, el urbanismo y el cine proponiendo una "práctica del espacio" que deviene "cartografía afectiva": una forma de redefinir las conexiones entre el adentro y el afuera, lo intimo y lo público, la casa y la ciudad, la biografía y la memoria colectiva.
\end{abstract}

Palavras-chave: Cine. Chile. Pensamiento espacial. Afectividad.

Vivir es pasar de un espacio a otro haciendo todo

lo posible para no darse un golpe.

Georges Perec. Especies de espacios.

Diversos estudios en cultura audiovisual han abordado las relaciones entre cine, arquitectura y urbanismo focalizándose en las imágenes exteriores, panorámicas, fachadas de edificios y cityscapes, que encontramos, en las primeras décadas del siglo, en los filmes del género conocido como "sinfonías de ciudad" (SHIEL, 2001) o, más tarde, en aquellas urbes imaginadas por el cine de ciencia ficción (BARROS, 2011). Ciertamente la ciudad es inseparable de sus imágenes: la experiencia de la vida urbana, y las nuevas concepciones de tiempo y espacio, alimentaron el nacimiento del cine pero éste, a su vez, hizo posible aprehender y reinventar la ciudad. Como, antes que representar, el cine interviene en el espacio una forma posible de entender ese fenómeno es considerar la categoría de "práctica espacial". Desde una perspectiva de geografía humana, Michel de Certeau (2000) concibió el espacio como resultado de una práctica de movilidad de los cuerpos a través del territorio. Ese andar de los individuos configura una enunciación por la cual, como resultado del movimiento, de la práctica, los "lugares" adquieren nuevos sentidos que los convierten en "espacios". La ficción es entendida también, desde esta perspectiva, como una propuesta de desplazamiento en la que toda historia sería una historia de viaje, una práctica espacial, cuyos "recorridos" hacen ver los "lugares" de un modo particular y los convierten en "espacios" (2000, p. 116). Si bien de Certeau analiza los tránsitos citadinos y nunca se refiere directamente al cine, el énfasis en las trayectorias y en las prácticas es aplicable al cine. Muchos

\footnotetext{
* Doctora en Romance Studies por la Universidad de Cornell. Investigadora en el CONICET y miembro del Núcleo de estudios sobre la intimidad, los afectos y las emociones y del Seminario sobre Género, Afestos y Política. E-mail: ireni22@gmail.com.
} 
aspectos de la imagen en movimiento tienen que ver con los actos de habitar y atravesar el espacio: las películas realizan "recorridos" de sus espacios pero, al mismo tiempo, el aparato cinematográfico reinventa esos espacios antes que reproducirlos miméticamente (CRESSWELL y DIXON, 2002, p. 7-11).

Entonces, el cine permite "mirar" el territorio al mismo tiempo que "práctica el espacio", lo produce, de un modo que según, la historiadora del arte Giuliana Bruno, refuerza los vínculos entre arquitectura y urbanismo no sólo en términos de la percepción visual, sino al proponernos experimentar vicariamente distintas maneras de habitar o atravesar espacios físicos y afectivos ${ }^{1}$. En su Atlas of Emotion, Bruno rescata un cine guiado por una práctica cartográfica del espacio que designa una "ruta háptica", una "geografía móvil" en donde paisajes, recorridos e inscripciones hacen coexistir cartografías interiores y exteriores, formas que vienen a poner en duda el hermetismo de la intimidad, transformando lo exterior/interior en un espacio poroso, de flujos y contaminaciones $(2002$, p. 11). En esta práctica móvil del espacio, el cine sería una forma de cartografía sensible de una manera particular a la dimensión de los afectos, una guía de pasajes que disuelven las demarcaciones fijas entre distintos espacios y entre los sujetos y las materialidades que los rodean. De este modo, como un arte peculiarmente espacial, el cine ha llevado la relación entre arquitectura y urbanismo a una escala más personal e íntima. Influenciados por la psico-geografía y la "deriva", algunos filmes configuran el espacio de la ciudad a partir de texturas, de entramados, de cruces de miradas y trayectorias, que vinculan lugares y grupos particulares. Así, como dramas móviles del espacio, ciertas películas no sólo ejemplifican problemáticas ya elaboradas por la arquitectura y el urbanismo como campos de saber específicos, sino que exploran, desde el discurso audiovisual, nuevas formas de pensar la superposición y los pasajes entre espacios cerrados y abiertos, visibles e invisibles, públicos y privados.

Desde un abordaje atento a los cruces entre teorías del espacio y afectividad, este artículo analiza los modos en que el documental El otro día (2012), del cineasta chileno Ignacio Agüero ${ }^{2}$, redefine los vínculos entre los modos de pensamiento espacial de la arquitectura, el urbanismo y el cine proponiendo una "práctica del espacio" que deviene "cartografia afectiva": una forma de redefinir las conexiones entre el adentro y el afuera,

\footnotetext{
1 Tempranamente, en "Site-seeing: Architecture and the Moving Image" (1997), Bruno señala la necesidad de reinscribir el cine en el terreno de las artes y las prácticas del espacio y de pasar de un paradigma óptico a uno háptico: "Siteseeing is a "passage," out of the theory of the gaze. Many aspects of the moving image -for example, the acts of inhabiting and traversing space - could not be explained within the framework of theories of the eye. Locked within a fixed gaze, the film spectator was turned into a voyeur. Speaking of siteseeing implies that, because of film's spatio-corporeal kinetics, the spectator is a voyageur rather than a voyeur. Through this shift to voy(ag)eur, my aim is to reclaim female mobility, arguing, from the position of a (film) voyageuse, that film is modern cartography. It is a mobile map" (1997, p. 10).

2 Destacado documentalista chileno, estudió arquitectura en la Universidad Católica entre 1970 y 1972 , luego continuó su formación en la Escuela de Artes, titulándose como Director Artístico con mención cine en 1979. Director y productor independiente, su filmografía se extiende por cuatro décadas e incluye los cortometrajes Hoy es jueves cinematográfico (1972), El gato (1976) y Animal de costumbre (1978) y los documentales No olvidar (1982), Como me da la gana (1985), Cien niños esperando un tren (1988), Sueños de hielo (1993), Neruda, todo el amor (1998), Aquí se construye (o ya no existe el lugar donde naci) (2000), La mamá de mi abuela le contó a mi abuela (2004), El diario de Agustín (2008) y El otro día (2012). También ha sido actor en películas de ficción y series para televisión, ejerciendo además la docencia en el departamento de comunicación de la Universidad de Chile.
} 
lo íntimo y lo público, la casa y la ciudad, el presente y el pasado, la biografía y la memoria colectiva. En el documental, la atención privilegiada al gran ventanal, que conecta el jardín interior con el resto de los ambientes de la casa, y a la puerta principal, a la que en el transcurso del documental llegaran extraños, señala la importancia de estos "pasajes" como espacios de contacto entre el adentro y el afuera. En El otro día son precisamente estos "espacios intermedios", lo que redefinen la subjetividad de una voz que comienza narrando en primera persona la historia familiar pero, al verse "interrumpida", por la luz que entra desde el jardín o por el sonido del timbre, se distrae y comienza a enmarañarse con los relatos de la vida de los otros que habitan, o habitaron, un mismo paisaje.

Si en El otro día se opera un marcado "giro afectivo" en el documental, la obra anterior de Agüero ya evidenciaba un interés por distintos modos de pensamiento espacial de la arquitectura y del urbanismo. Casi todos los documentales de Agüero, aun cuando abordan temáticas ligadas a la dictadura de Pinochet, nacen de la construcción y lectura de espacios ${ }^{3}$. Sus películas interrogan los sentidos a la vez históricos e íntimos del habitar, las transformaciones y la intrínseca precariedad del entramado urbano y, desde una matriz deambulatoria, revelan la segregación social de Santiago. Esto último se evidencia sobre todo en Aquí se construye (o ya no existe el lugar donde naci) (2000), que se inicia con una cámara que filma a una señora vaciando su casa, la que luego será demolida por grandes máquinas, dejando el terreno libre para la construcción de un edificio. En este documental, la desaparición del paisaje arquitectónico de la burguesía santiaguina, representado por casas antiguas con jardines, y el desarrollo avasallante de la especulación neoliberal, se cruza con las vivencias particulares de los obreros que trabajan en las nuevas edificaciones y a los que la cámara sigue en sus trayectos desde su lugar de trabajo en el barrio burgués, hacia la periferia donde viven. En un artículo sobre cine chileno y espacio urbano, Valeria de los Ríos (2010, p. 13) plantea que Aquí se construye funcionaría como un antídoto contra la desorientación postmoderna, articulando "mapas cognitivos" para la reapropiación de un espacio urbano que cambia a un ritmo vertiginoso. En el documental, tanto el vecino de la construcción, como uno de los trabajadores, reconstruyen su historia familiar y las implicancias de la destrucción del espacio circundante mientras relatan las condiciones mediante las cuales llegaron a vivir allí. Así, en el registro fílmico se inscribiría la violencia de la mutación desorientadora del espacio urbano al mismo tiempo que se elaboraría un "mapa cognitivo" de la ciudad mediante la introducción de categorías de

\footnotetext{
${ }^{3}$ Filmado clandestinamente, el cortometraje No olvidar (1982) se centra en el espacio de los hornos de Lonquén y desde allí reconstruye la matanza de unos campesinos a manos de la policía durante el régimen dictatorial de Pinochet. En Cien niños esperando un tren (1988), a través del seguimiento de los talleres de cine para niños realizados por Alicia Vega en la población de Lo Hermida, Agüero logra dar cuenta de las formas de habitar un espacio dominado por la marginación, la exclusión y la violencia social y política. El procedimiento de observar un lugar, del cual decanta una historia, es claro también en $L a$ mamá de mi abuela le contó a mi abuela (2004) en donde el director visita la localidad rural de Villa Alegre, en la zona central de Chile, y encuentra allí a un grupo teatral realizando un taller en el que se invoca la memoria colectiva oral del lugar y se invita a los habitantes del mimos a "representar" su propia historia. El cine de Agüero se desplaza también al espacio exterior en un sentido más radical cuando, en Sueños de hielo (1992), acompaña la travesía de un témpano, que había sido capturado en la Antártida para ser llevado al pabellón chileno de la Exposición Universal de Sevilla, pero acaba deconstruyendo, lúdica y poéticamente, el discurso nacional épico de Chile como país frio.
} 
temporalidad que permiten entender la transformación de los barrios de Santiago (idem, p. 5-7).

El otro día da cuenta de un microcosmos doméstico similar al de Aquí se construye: la propia casa del director, antigua con jardín, ubicada en una calle pequeña, en un barrio residencial de la zona oriente de Santiago que aún resiste la invasión de los edificios, es el punto de partida de una historia que parte del "adentro", el hogar y la historia de su familia, para abrirse de manera aparentemente azarosa al "afuera" de la vida de los otros. El plano que une y separa esos dos mundos es el sonido del timbre. Agüero recibe a desconocidos que por motivos diversos tocan a su puerta, les cuenta que están siendo filmados y les comunica su deseo de visitarlos en sus casas. Su hogar se convierte en el centro desde el cual se configura un mapa inesperado de Santiago, que el director colgará en la pared y utilizará como carta de navegación en su expedición por los barrios donde viven aquellos que habían tocado su puerta. En ese ejercicio se articula un modo de pensamiento espacial que revela uniones de personas paradójicamente separadas, debido al espacio geográfico y social que los distancia. Pero, a diferencia de Aquí se construye, El otro día no articula un "mapa cognitivo" que incluye a la memoria individual como pilar de orientación sino que se presenta, más bien, como una "cartografía afectiva" en tanto redefine los vínculos con los otros al mismo tiempo que apuesta a la propia materialidad del cine -a las impresiones visuales, táctiles y sonoras de ese medio- para explorar los límites borrosos y los inesperados "pasajes" entre espacios y tiempos.

\title{
LA CASA O REVERBERACIONES DEL YO EN LA "CÁMARA OSCURA"
}

\author{
Affects not only are makers of space but are themselves configured as space, \\ and they have the actual texture of atmosphere. To sense a mood is to be sensitive \\ to a subtle atmospheric shift that touches persons across air space (...) \\ To address this language involves a tangible redressing of visual space, \\ because the affect is not a static picture and cannot be reduced to \\ optical paradigms or imagined in terms of optical devices and metaphors. \\ The landscape of affective mediation is material: it is made of haptic fabrics, \\ moving atmospheres, and transitive fabrications. \\ Giuliana Bruno, Surface: Matters of Aesthetics, Materiality, and Media.
}

En su estudio sobre los vínculos entre el cine y la arquitectura, Anthony Vidler destaca que la interacción mutua entre estas dos "artes espaciales" se alimenta tanto del rol de los arquitectos en la construcción del "decorado" como de la habilidad del cine de "construir" su propia arquitectura mediante el trabajo de luces, sombras, escala y movimientos de cámara (1993, p. 46). "Quise hacer una película en la cual, cuando me levantara, ya estuviera en el set", ha dicho Ignacio Agüero en una entrevista sobre $E l$ otro día, lo que nos hace pensar en la particularidad de esa filmación (MARIN, 2013, $\mathrm{s} / \mathrm{n}$ ). La arquitectura y el cine, como dos prácticas espaciales, confluyen aquí en la persona del director: el set de la película es su propia casa que, gracias a sus conocimientos de arquitectura, había reformado en el pasado para darle mayor 
luminosidad ${ }^{4}$. Pero también son con los planos, el juego de luces y sombras y los movimientos morosos pero calculados de la cámara, que recorren el interior de esa casa, los que ayudan a vislumbrar el sentido enigmático de los objetos cotidianos que forman parte, según Vidler, del potencial poético del cine como arte del espacio (1993, p. 57).

La pantalla en negro que precede a los títulos de El otro día se acompaña de una banda sonora con ruidos marinos. Un plano medio, casi abstracto, sigue el juego de luces y sombras sobre una pared y deja ver el contorno borroso de una figura verde y marrón reflejada en un fragmento del espejo de un mueble. Un travelling lateral de izquierda a derecha sigue la entrada de la luz solar por la ventana a medida que pega sobre la pared, mientras el sonido del mar es reemplazado por ruido de labores domésticas en el fuera de campo y por el canto de los pájaros que llega desde el jardín reflejado en ese fragmento de espejo. Escuchamos sonido de lluvia y luego vemos planos del ventanal. A través de éste, la cámara sigue morosamente a un gato jugando en el jardín y luego a un pájaro que se acerca a tomar agua. Al sonido de la naturaleza se yuxtapone el ruido de los autos y un nuevo plano general algo borroso muestra el ventanal y las hojas de los arboles que se recortan de la oscuridad y se imprimen, junto al rocío de la humedad, en el vidrio. Con otros planos cercanos observamos los estantes de la biblioteca y detectamos libros, dibujos infantiles, afiches, películas, fotografías en color y en blanco y negro, mientras desde el fuera de campo llega el sonido de un piano y luego el timbre de la puerta.

Las primeras escenas de El otro día carecen de narración vocal (la voz narradora en primera persona recién entrará a los 20 minutos) pero no de voces: el deambular de la cámara establece un diálogo entre el adentro y el afuera y entre la quietud y el movimiento. El ejercicio de contemplación es un relevamiento del espacio que tiene algo de arquitectónico. Como plantea Roger Koza (2013), "los movimientos que registran las paredes cubiertas de fotografías, películas, pinturas, libros y mapas y los enormes ventanales de su casa se revelan peculiarmente arquitectónicos, como si el propio director sintiera la cámara como una prolongación de una escuadra imaginaria con la que mide el espacio de su intimidad exteriorizada en ese hogar" ( $\mathrm{s} / \mathrm{n}$ ) pero hay también en el movimiento de ida y vuelta entre el afuera y el adentro un intento de pensar los pasajes. En un momento Felipe, el hermano mellizo del director, se sienta junto a la ventana con un ejemplar en las manos de Especies de espacios, un libro en el que Georges Perec propone una investigación íntima e histórica sobre el habitar y en donde el espacio es "todo aquello que frena la mirada" (123). Es decir, los objetos que se interponen ante los ojos o los pies pero también los pasajes: las puertas y ventanas que nos separan y conectan del espacio de los otros.

Para Le Corbusier la casa era una máquina para mirar el mundo en la que, a través un recorrido por un espacio interior -“fabricado por imágenes y no por muros"-, las

\footnotetext{
${ }^{4}$ Qué historia es ésta y cuál es su final (2013), el documental de José Luis Torres Leiva sobre Ignacio Agüero, realiza un recorrido de sus películas al mismo tiempo que habla de las casas en donde el director vivía al momento de filmarlas. En el documental, Agüero aparece sentado en el living de su casa revisando, junto a su montajista Sophie França, las fotos de las distintas casas en las que ha vivido. En un momento, se muestran fotos de la reforma de la casa actual de Agüero -la misma que aparece en El otro día-y el director-arquitecto comenta sobre la eliminación de la galería en donde ahora es el ventanal el que comunica la cocina con el jardín interior.
} 
personas podían experimentar los espacios desde una situación de dominio (KALE, 2005, p. 5). Si en el diseño moderno, los grandes ventanales le permitían al dueño de casa unirse al mundo y controlarlo, desde una distancia que deja ver al mismo tiempo que evita el contacto, quizás pueda relacionarse el énfasis del documental en la oscuridad del interior y en la luz que llega desde el exterior con la figura de la "cámara oscura" 5 . En su estudio sobre visualidad y poder en la modernidad, Jonathan Crary (1990) plantea que, durante los siglos XVII y XVIII, el modelo de "la cámara oscura" se presentó como una metáfora dominante para la visión humana, para describir una relación entre el objeto observado y el objeto de la observación en la que produciría una operación de individuación porque se supone un observador aislado, encerrado y autónomo dentro de un espacio "oscuro". Según Crary, este paradigma se representa muy bien en "The Geographer", una pintura de Vermeer de 1668 que muestra un hombre solitario en los confines de un interior sombrío solo iluminado por una ventana. Como si el conocimiento exterior no resultara de una exanimación sensorial directa, sino de un sondeo mental de su representación clara dentro de la habitación, el personaje en la pintura le da la espalda a la ventana pero se concentra en una carta náutica. Al producir una especie de "retirada del mundo", como modo de regular y purificar la relación del individuo con la diversidad de contenidos de lo que es ahora el mundo "exterior", la camera oscura es inseparable de una cierta "metafísica de la interioridad": es una figura tanto del observador como nominalmente sujeto libre y soberano, como así también un sujeto privatizado confinado a un espacio cuasidomestico, aparentemente separado del mundo público exterior (1990, p. 248).

La película de Agüero parece partir de la metáfora visual de la cámara oscura pero las huellas lumínicas en la superficie interior van produciendo una experiencia del habitar y atravesar los espacios que termina difuminando cualquier sentido de demarcación clara. Según Bachelard el lugar de identificación y de intimidad por antonomasia es la casa (2000). En la base de todo lugar de intimidad parece hallarse el concepto de habitar, concepto que por Heidegger (1994) corresponde a la esencia misma del hombre: el hombre es hombre en cuanto habita y habitar es permanecer en paz en un espacio, mantenerse en él y, gracias a esto, poder recorrer ese y otros espacios. En otras palabras, un elemento fundamental del espacio del habitar es el límite: sólo en un espacio delimitado el ser humano puede identificarse, habitar. Pero, en El otro día, si el espacio habitado se configura como un interno, éste nunca es cerrado. Al igual que los artistas e intelectuales del siglo XIX analizados por Crary, que

\footnotetext{
${ }^{5}$ La cámara oscura es un instrumento óptico que permite la formación de imágenes lumínicas reflejadas a partir de un espacio oscuro y cerrado con un pequeño orificio como única entrada de luz, lo que permite invertir la imagen del mundo exterior ajeno y sobreimprimirla en el interior familiar y propio. Más allá de ser el principio de la fotografía, la cámara oscura, como dispositivo visual, ha sido utilizada para pensar nociones de habitabilidad y convivencia en la configuración del espacio urbano. En el urbanismo contemporáneo, esta tecnología antigua es utilizada para pensar, desde la estética, una idea de "habitabilidad". Cuando en los festivales de arquitectura se instala "cámaras oscuras" en los interiores de casas particulares o edificios públicos, el paisaje exterior invertido y reflejado en el interior domestico, y en las mismas personas que lo habitan o transitan, permite a los individuos experimentar el ingreso de la ciudad en la arquitectura y la puesta en cuestión de los límites entre el adentro y el afuera. Además de la cámara oscura, los festivales de arquitectura, como 48hs Open House, trabajan sobre la idea de vecindad y convivencia al promover la visita de la casa de ciudadanos comunes que dejan "sus puertas abiertas" durante dos días.
} 
terminarían produciendo una "uprooting of vision from the stable and fixed relations incarnated in the camera obscura" (p. 278), las huellas lumínicas y sonoras que deja a su paso el exterior sobre la superficie interior de la casa de Agüero van "produciendo" a la voz narradora, activan su ejercicio de memoria, su capacidad cognitiva y su impulso de exploración sensible y afectiva.

La historia comienza con una impresión lumínica del exterior del jardín en el interior y es también el exterior sonoro de la calle el que va puntuando las inflexiones del relato en primera persona. Agüero filma detenidamente su jardín, los cuadros y algunos otros objetos que adornan su casa, pero sobre todo el modo en el sol avanza sobre la foto de sus padres. Transcurridos los primeros veinte minutos, el cineasta murmura: "La coincidencia del otro día, de la posición de la fotografía en el armario con la luz del sol que la iluminó, con las hojas que le hicieron sombra, con el hecho de que yo estaba justo en ese momento ahí, filmando, coincidencia que se da muy pocas veces o quizás una sola vez, hace que sea aquí donde comienza la historia. Por ejemplo: puedo decir que los de la fotografía..." (el énfasis es mío). El timbre que suena interrumpe el relato de Agüero pero éste intenta retomar: "Por ejemplo puedo decir que los de la fotografía... son mis padres recién casados, en 1945, en la isla Quiriquina", hasta que nuevamente la llamada de la puerta deja en suspenso la evocación del inicio de la historia personal.

"Las largas tomas de grupos de frutas, sombras proyectadas en un muro, movimientos de árboles vistos a través de una ventana o el golpetear de una gotera en un día de lluvia parecen por momentos naturalezas muertas, construidas con el cuidado de un cuadro de esos géneros que Todorov calificó de 'elogio de lo cotidiano', pero desprovistas de la solemnidad a veces pretenciosa de los bodegones barrocos" dice Fernando Pérez (2014, s/n) al dar cuenta de la plasticidad en el cometido constante de Agüero de dar cuenta del tránsito de la luz sobre las cosas. Mediada por la pintura se establece un vínculo entre cine y arquitectura que piensa el espacio en términos de "texturas", lo que permite una consideración de la esfera de lo sensible que supone también un modo de relación entre individuo y entorno. Partiendo del termino deleuziano de 'recollection-image', Laura Marks analiza la habilidad del cine de evocar memorias al detenerse en los 'recollection-objects', aquellos objetos portadores de una historia condensada pero cuyos sentidos no son solo codificados audiovisualmente, sino que se expresan también por la habilidad háptica del filme, por su capacidad de evocar el sentido de lo táctil (p. 81-84) ${ }^{6}$. En su relación "textural" con los objetos, la película abre el campo tanto para la percepción como para la sensación: para una relación visual

\footnotetext{
${ }^{6}$ En su estudio sobre la visualidad háptica, Laura Marks refiere a estas imágenes como potencias sensoriales porque participan de una dimensión háptica más próxima a la dimensión táctil. Las imágenes borrosas invitan a una percepción más próxima a la superficie y a la materialidad misma, donde el ojo se queda explorando el grano y la textura, pequeños eventos que emergen en la superficie del plano. Una mirada más íntima que reduce la distancia y confunde observador y superficie observada. Mientras en la visualidad óptica el ojo percibe los objetos desde una distancia lo suficientemente lejana que los aísla como formas en el espacio, en contraposición a esta separación entre el cuerpo del que ve y el objeto, la visualidad háptica sería un modo más cercano de mirar, ya que tiende a moverse sobre la superficie de los objetos, antes que zambullirse en una profundidad ilusoria, y no busca tanto distinguir formas sino discernir texturas. En este sentido, la visión háptica se basaría más en el tacto y estaría más cercana a una forma corporal de percepción como si los ojos en sí mismos fueran "órganos del tacto" (2000, p. 162).
} 
en la cual se mantiene una demarcación entre objeto y sujeto pero también una experiencia por momentos autorreferente en donde objetos y sujeto pierden las líneas de demarcación. Es en esta experiencia perceptiva y sensorial en la que aflora el afecto como un modo distintivo de experimentar el espacio construido. La morosidad de la cámara hace que el documental funcione como un dispositivo sensorial que captura la fuerza afectiva de los espacios, de los objetos y es en esa dimensión que se da lugar a una "topografía de los afectos" en donde, lejos de limitarse a las fronteras de un yo psicológico o a una narrativa basada en la primacía de la interioridad, el afecto se "abre" al campo social. La evocación de fragmentos de la vida de sus padres se va entreverando con la historia colectiva nacional cuando, frente a esta foto, Agüero se pregunte de manera susurrada y entrecortada qué habría dicho su padre, marino, al enterarse que décadas más tarde uno de sus hijos sería torturado por otros marinos y en otra escena, al seguimiento del gato en el jardín se sucedan imágenes de restos humanos, planos extraídos de No olvidar (1982), un documental de Agüero sobre la represión durante la dictadura de Pinochet.

La película fluye de un espacio al otro también en otro sentido. Según Adrián Martín es en el "espacio fantasmagórico" en donde se da el verdadero encuentro de la arquitectura y el cine ( $\mathrm{s} / \mathrm{n})$. Agüero se aboca a esa "metamorfosis íntima" cuando decide intercalar imágenes de la casa con fragmentos de sus propias películas o de películas de otros filmadas en ese mismo espacio. Una forma de tratar el espacio íntimo del hogar, con su memoria encarnada y sus espectros: los fantasmas de los padres pero también aquellos del cine. Por apenas unos segundos -sacados de un rodaje de La recta provincia que se realizó en la casa de Agüero- vemos a Raúl Ruiz diciendo "acción" frente al ventanal de la casa que da al jardín y desde donde personajes inexpresivos miran hacia el interior. El espacio más íntimo y edénico de la casa parece habitado por espectros. $\mathrm{Si}$, como micromundo aparcelado el jardín es un espacio "heterotópico", una reinvención de la "naturaleza" dentro de un espacio urbano ${ }^{7}$, Agüero vuelve a intervenir ese espacio híbrido. El salvavidas colgado en un extremo le da un "aire marino" al pequeño jardín y los ventanales que cierran ese espacio parecen los bordes de una pecera. Espacios híbridos y formas de pasaje que van desdibujando las demarcaciones y los límites entre interior y exterior. En los intersticios de las huellas lumínicas, que llegan desde el jardín y se imprimen en el interior de la casa, "reverbera un yo", una subjetividad que recibe también las huellas sonoras que vienen del fuera de campo. Las personas que tocan el timbre de su casa, y a las que el director visitará, convierten la ecografía en cartografía, al volver a introducir el azar como elemento inicial de un esfuerzo de "navegar hacia el otro".

\footnotetext{
${ }^{7}$ En "Of Other Spaces" (1986, p. 24), Michel Foucault define el microespacio del jardín en términos del concepto de "heterotopía" en tanto es un híbrido de espacios, un lugar real, localizable, pero al mismo tiempo apartado e ilusorio, de alguna manera está más allá del mismos espacio que lo contiene.
} 


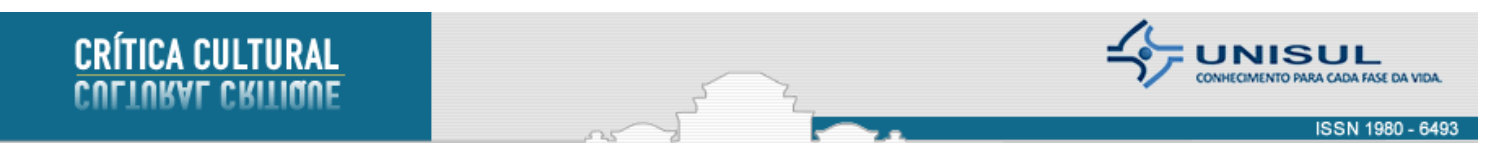

Figura 1: Formas y texturas

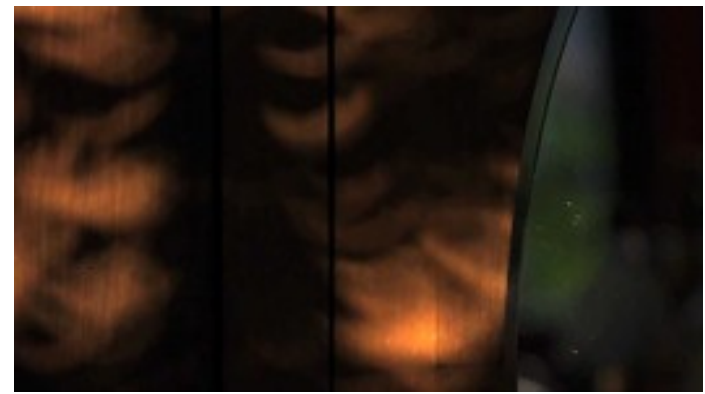

Figura 3: Jardín

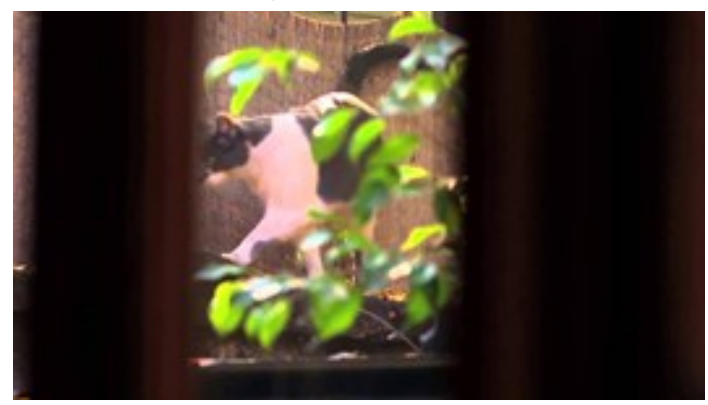

Figura 5: Foto de los padres

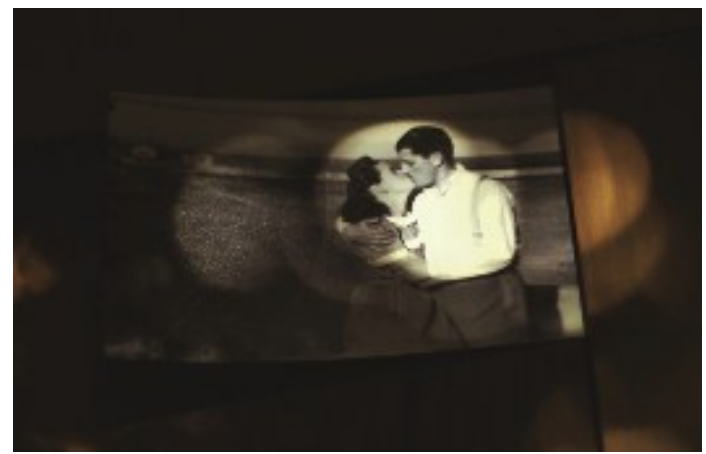

Figura 7: El fantasma de Raúl Ruiz

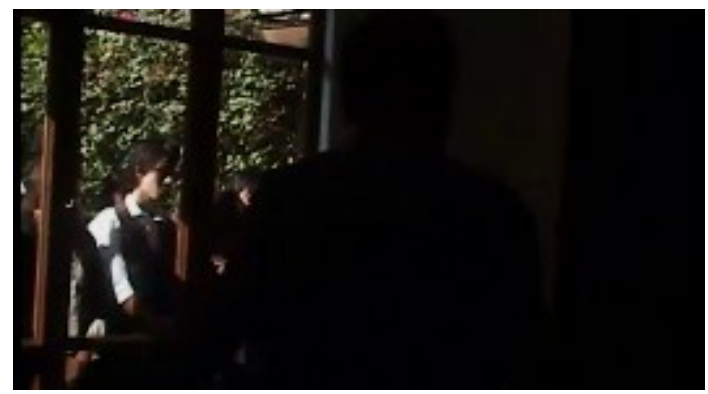

Figura 2: Exterior reflejado en interior

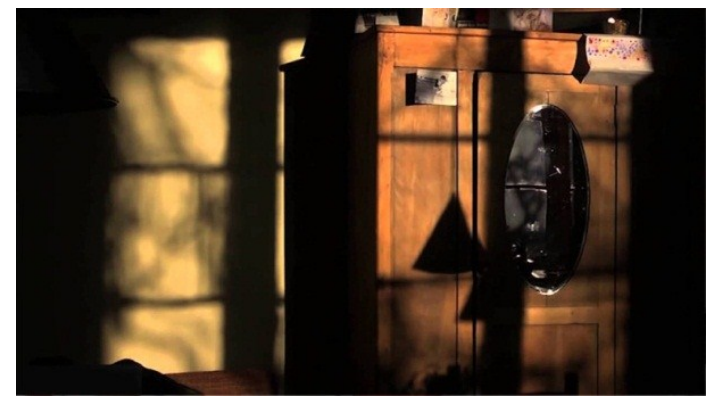

Figura 4: Ventanal

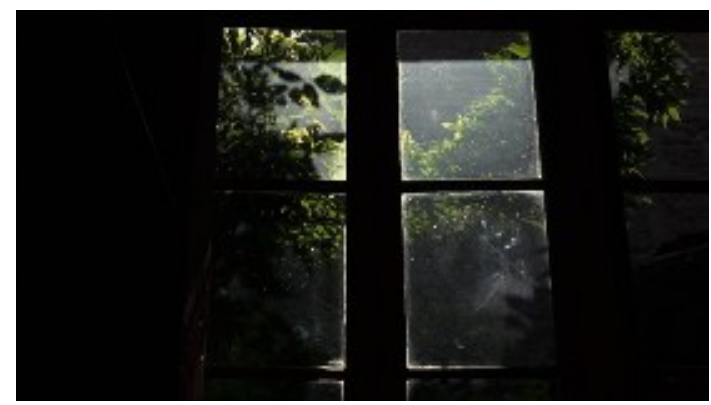

Figura 6: Objetos personales

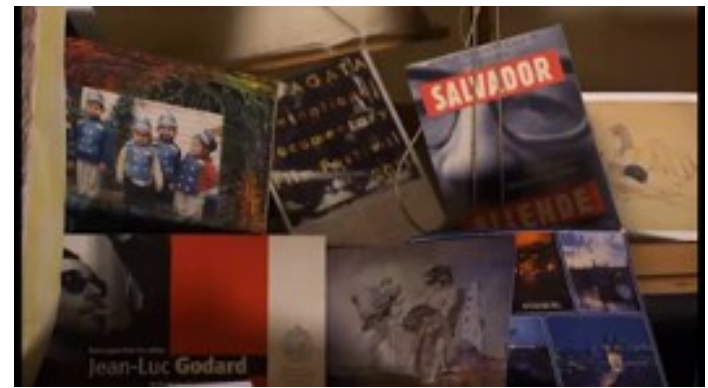

Figura 8: Una familia con "aire marinero"

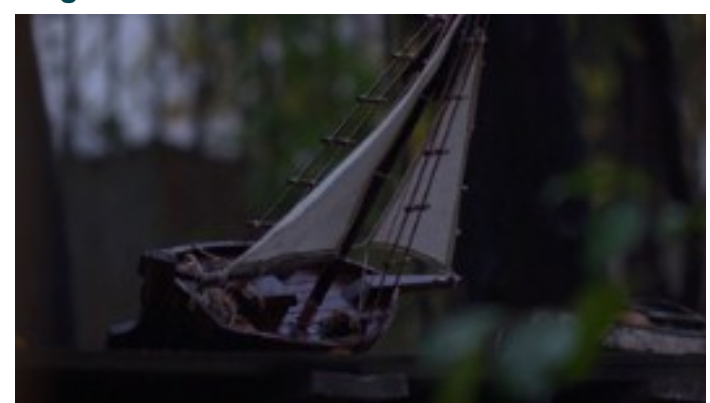

\title{
LA CIUDAD O DE LA CARTA DE NAVEGACIÓN HACIA EL OTRO
}

\begin{abstract}
Space is the dimension that presents us with the existence of the other; space is the dimension of multiplicity. (...) It is space that presents us with the question of the social. And it presents us with the most fundamental of political of questions which is how are we going to live together.

Doreen Massey, For Space.
\end{abstract}


"Estoy haciendo un documental sobre la gente que toca el timbre de mi casa", dice Agüero a todo aquel que llega a su puerta. En El otro día los transeúntes tocan el timbre de la casa del director, situada en una tranquila calle del barrio de Providencia: piden limosna, permiso para estacionar, venden chucherías, buscan trabajo. Agüero los recibe, les cuenta eventualmente que están siendo filmados, les pregunta sobre algunas cuestiones personales y luego les comunica su deseo de visitarlos otro día en sus casas. A partir de un acontecimiento tan cotidiano y azaroso como es tocar el timbre de una casa, Agüero comienza a articular un relato sobre la ciudad y las personas que la habitan. Así va elaborando un mapa inesperado de Santiago, de algunos de recorridos y de quienes los ejecutan, de la segregación y de la pobreza. En un momento, el director despliega en una pared un plano y empieza a marcar los puntos por visitar: Pedro Aguirre Cerda, Lo Espejo, San Joaquín. Cuando la cámara se traslada a estos espacios, se encuentra con otros nombres, otros rostros, otros mundos: con un ex convicto, con un escritor dedicado a la mecánica, con una barrendera, un joven viudo con tres hijos, una mujer de mediana edad que vive de la limosna, un cartero, una joven estudiante de cine de Valparaíso que terminará haciendo los créditos de la película.

Según Doreen Massey, el espacio modula nuestro entendimiento del mundo, nuestras relaciones y actitudes frente a los otros, nuestra política. El espacio es una imbricación de trayectorias siempre abierta al azar, un espacio marcado por multiplicidades, por el encuentro con "el otro" (2012, p. 5-9). En su atención privilegiada a los "pasajes", Georges Perec plantea que "vivir es pasar de un espacio a otro haciendo todo lo posible para no golpearse" (1999, p. 25), sugiriendo que la navegación es siempre dificultosa. Atravesar un espacio es abrirse al encuentro y al choque y esta fricción se evidencia en la frustrada primera "entrevista" de Agüero en la película cuando el hombre desocupado, que había tocado a su puerta para vender alfajores, se niega a decirle su nombre. Georges Perec (idem, p. 127-9) propone "imaginar el lugar que ocupan los otros" y "jugar con el espacio". Pese a la negativa del hombre de la puerta, en el siguiente plano, vemos al director desplegando en una pared un mapa de Santiago y marcando una localidad de la periferia. Un paneo nos muestra la distancia pero Agüero decide "jugar" con el espacio, eliminando el viaje. Como si hubiera un vacío en el trayecto, la cámara se desplaza por el mapa para llegar en el siguiente plano al lugar. Si su casa antigua, con patio interior, es como un pequeño oasis, la periferia de los que toman el Transantiago para ir a los barrios más acomodados se ve hostil. Animales y autos conviven al costado de una autopista en una localidad precaria y pobre del Gran Santiago. En su lectura del filme, Roger Koza plantea que Agüero reemplaza el mito de la ciudad como "jungla de cemento" por la idea de "ciudad como archipiélago" ya que filma la expedición como si fuera un marino: marca en el mapa los signos de sus visitas con un alfiler y un hilo rojo que une la casa que ha visitado con la suya. El "aire marino" de su familia deviene en una configuración visual de una red afectiva insospechada entre él y los otros. Así, Agüero "juega” con el espacio y produce un deslizamiento de la topografía de lo sensible en el interior del hogar a una "cartografía afectiva" que da cuenta de los vínculos con los otros en el presente.

Pero en el desplazamiento geográfico, en las varias idas y vueltas de su casa a la periferia, también se va articulando una cartografía afectiva que posibilita una lectura del pasado. De mapas afectivos en un sentido metafórico habla Jonathan Flatley cuando plantea que ciertas obras o prácticas estéticas pueden pensarse en términos de una 
"cartografía afectiva" no solamente porque representan espacios concretos, sino porque ponen en evidencia la vida afectiva del lector/espectador de un modo que la redirecciona al mundo histórico y a la vida afectiva de los otros que habitaron los mismos paisajes. Algunas obras establecen esos vínculos por medio de un "extrañamiento" que transforma la vida emocional -el rango de estados de ánimo, estructuras de sentimiento y vínculos afectivos - en algo raro, sorprendente, inusual y, por lo tanto, capaz de generar un nuevo tipo de reconocimiento, interés y análisis. Este tipo de "extrañamiento afectivo" se evidencia en varios momentos en la película. Una de las primeras imágenes de la periferia nos deja ver a unos niños pobres jugando en la calle en Huecheruba. Los niños, de rasgos indígenas, se acercan a la cámara con una curiosidad que recuerda a la de esos otros niños filmados por Agüero en Cien niños esperando un tren. Cuando la cámara nos devuelve a la casa, se posa en una aeropostal de Eugenio Dittborn y recorre rostros, entre ellos el de Jimmy Button ${ }^{8}$ y la tapa del libro Darwin en Chile. Viaje de un naturalista, hasta detenerse en una foto de la familia del narrador que dice: "Aunque mi padre se retiró muy joven de la marina impregnó a toda la familia de un aire marinero. Mi hermana mayor se casó con un marino. Mi hermano mayor entró a la escuela naval. Mi otro hermano fue torturado por marinos y yo mismo tengo un título de marino por haber cruzado dos veces el mar de Drake".

Si el "aire marino" del padre extrañamente se traslada en la tortura del hijo, es también ese imaginario marítimo el que articula el juego de Agüero con el espacio y el tiempo. En otra secuencia del documental, la cámara deja de observar al gato que juega en el jardín para trasladarse al interior en donde, al atardecer, se comienzan a reflejar impresiones de los arboles sobre los muebles. Fundiéndose lentamente con estas imágenes del hogar aparece el mar de Drake, un plano extraído del documental de Sueños de Hielo, y es a partir de esta superposición de espacios sostenida en el tiempo que se inicia la "expedición urbana". En su Poética del espacio (2000), Gastón Bachelard plantea que ciertos paisajes se asemejan a la casa, el espacio de intimidad por antonomasia, por su capacidad de ser lugares donde el sujeto puede experimentar una "soledad constitutiva" de su ser. El mar, como una "inmensidad íntima" es, para Agüero, al igual que la casa, un espacio caracterizado por un vínculo de topofilia. De la mirada subjetiva de un barco pasamos a un plano de la periferia en donde el director entrevista a un ex convicto, drogadicto, sin trabajo y sin educación, que había perdido un pulmón por un balazo que recibió al intentar escaparse de la cárcel. Del Gran Santiago volvemos al hogar donde el director habla de la memoria de una historia

\footnotetext{
${ }^{8}$ En 1830 Fitz Roy, capitán del barco en el que también viajó Darwin, capturó un adolescente yámana y se lo llevó a Inglaterra. Rebautizado como Jemmy Button, el joven indígena fue sometido a un "proceso de occidentalización" en Europa y luego fue devuelto a su tierra de origen hablando dos lenguas pero también ninguna. La historia de este joven "se volverá en el campo artístico chileno, un significante del exilio. A principios de la década del ochenta, el artista conceptual Eugenio Dittborn empleó en alguna de sus famosas Pinturas Aeropostales (una serie de obras, entre pinturas y fotografías sobre papel, que eran plegadas, guardadas en sobres y enviadas por correos a diferentes países), la imagen impresa de Jemmy que provenía de un dibujo realizado por el mismo capitán Fitz-Roy y al que Dittborn agregó la leyenda "Exiliado fueguino Jemmy Button". En plena dictadura, Dittborn inventa un nuevo Jemmy al rodear el retrato del fueguino de otros rostros de desconocidos, apropiándose de lo que era un fragmento anecdótico del diario de Darwin y relocalizándolo en el centro de una nueva narrativa fragmentaria de supresión y resistencia, parte de una obra postal que viajaba en el espacio pero también en el tiempo, produciendo un movimiento de extrañamiento que construye comunidades con el pasado al recuperar y reinventar rostros, casi fantasmas que prefiguran y dominan el presente." (DEPETRIS CHAUVIN, 2015, $\mathrm{s} / \mathrm{n})$
} 
contada por su padre en la niñez. La cámara recorre el "collage" de objetos: afiches de Cien niños esperando un tren, de Salvador Allende y Nostalgias de la luz, documentales de su compatriota Patricio Guzmán, y una foto de su hijo Raymundo, cuando niño, disfrazado como el marino Arturo Prat para un acto escolar. La voz narradora dice que Raymundo "ahora tiene 16, dos más que cuando mi padre ingresó en la marina. 14 tenía también Jemmy Button cuando el capitán Fitz Roy lo raptó para llevárselo de la Tierra del Fuego a Inglaterra a bordo del Beagle. 14 años tenía Rosa cuando llegó del campo a trabajar a la casa de mi abuelo. Cuando Jemmy Button a los 16 regresó en el misma Beagle, abordo de la cual también venía Darwin, hablaba inglés y su padre había muerto. Rosa nunca regresó al campo. Se quedó para siempre en la casa de mi abuelo y no aprendió a leer ni a escribir". Desde una impronta benjaminiana, Jonathan Flatley propone una lectura histórica que apuesta a un anacronismo en donde los afectos nunca se experimentan por primera vez, sino que suponen un archivo de sus objetos previos. Serían las mismas obras de arte las que abrirían un espacio para el encuentro de esos objetos y afectos $\mathrm{y}$, en este sentido, la lectura histórica afectiva se moviliza en un recorrido que rechaza la linealidad del historicismo y propone pensar los modos en que el pasado deja una impresión en el presente (2008, p. 15). Si no son sólo las ideologías o los mapas cognitivos los que dan forma a nuestros comportamientos o prácticas, El otro día, como trabajo estético intenta mapear y movilizar los flujos afectivos de lo social. Las lecturas "digresivas" de Agüero evidencian, entonces, que, a diferencia de la dimensión interior de las emociones, los afectos indican algo transformativo que se experimenta en relación a objetos, estableciendo una relación en alguna medida fluida entre sujeto y objeto de la mirada.

Figura 9: Los que tocan el timbre

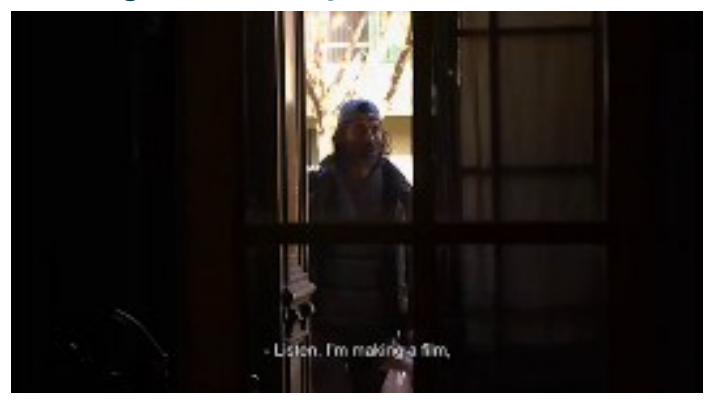

Figura 11. La periferia como isla.

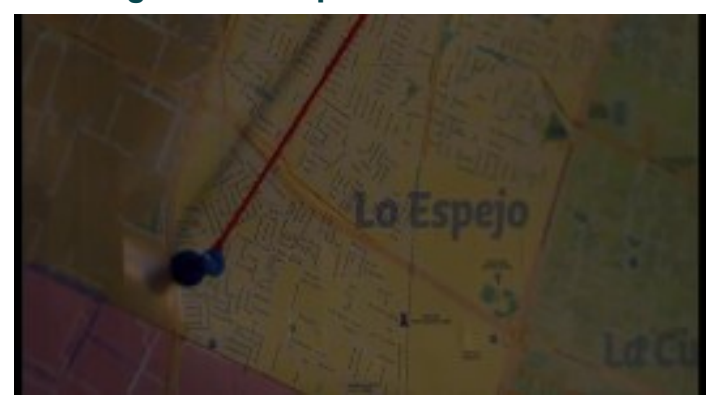

Figura 10: Carta marina

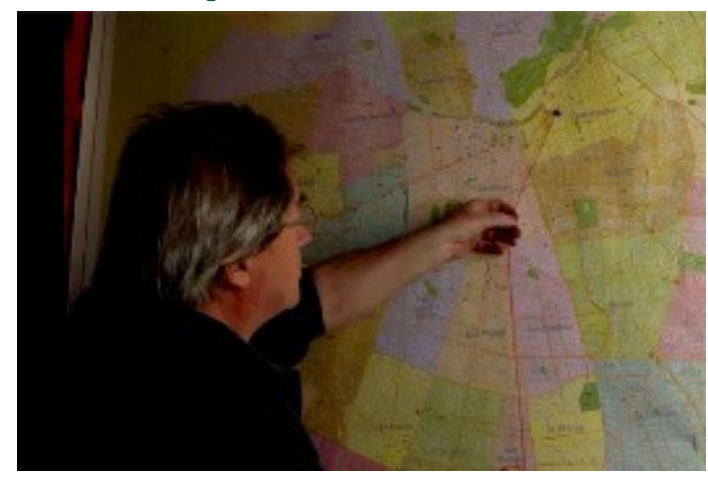

Figura 12. La vida de los otros

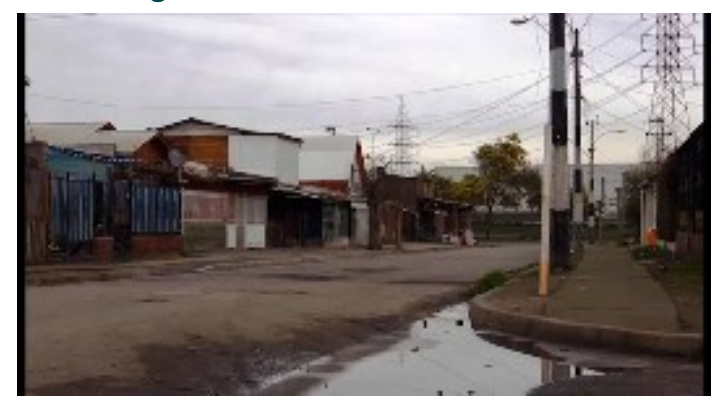


Figura 13. Superposición de espacios.

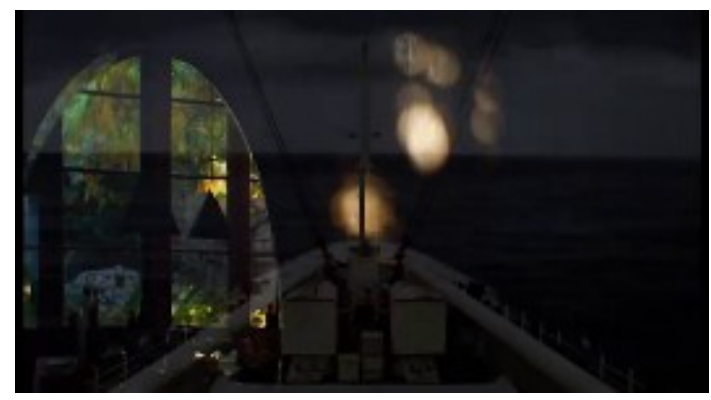

Figura 15: La casa de los otros

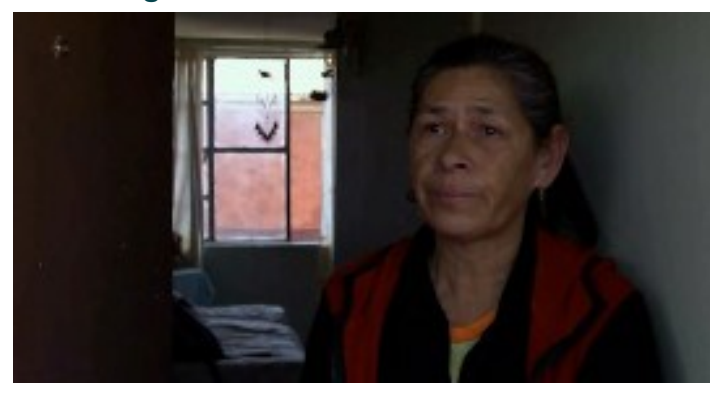

Figura 14: Mar de Drake

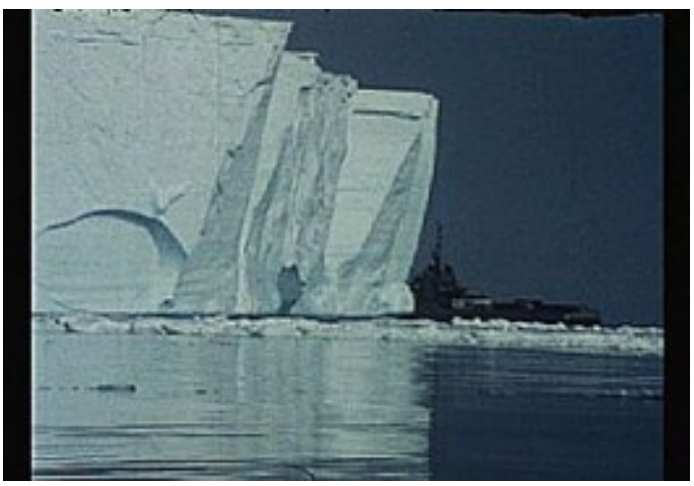

Figura 16: La ventana al mar

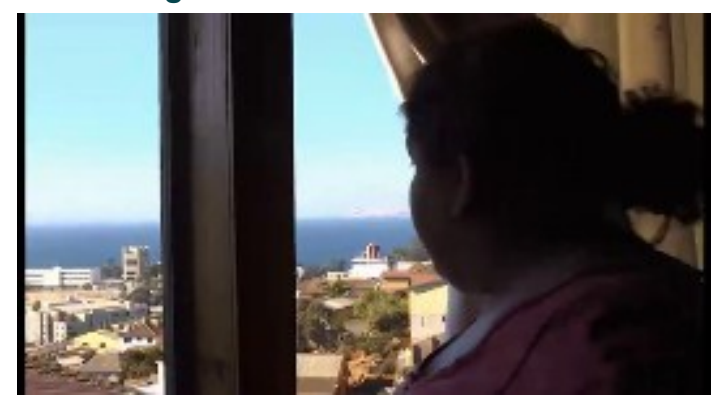

CÓMO VIVIR JUNTOS. PRÁCTICAS ESPACIALES Y CARTOGRAFÍAS AFECTIVAS

Relevando distintas formatos de los filmes (auto)biográficos, como diarios o autorretratos, Paola Lagos Labbé (2011, p. 65) sostiene que los discursos documentales que exponen lo íntimo se caracterizan por un rasgo introspectivo, una "operación ecográfica", donde diferentes recursos representacionales buscan dar forma a un espacio, un tiempo, y una voz que se combinan para evocar un "yo". Ciertamente, la película replica este movimiento hacia el interior, pero también construye la subjetividad "as a site of instability-flux, drift, perpetual revision-rather than coherence" (RENOV, 2004, p. 110) sobre todo porque, a pesar de que entramos en la casa por medio de una narración en primera persona, como si el hogar fuera una isla y el director un marino que circunnavega un gran archipiélago, la película termina abriéndose y llevándonos con ella hacia el afuera. Así, el gesto habitual de muchos películas (auto) biográficas que se basan en una narración personal y giran la cámara hacia el interior se duplica, en El otro día, con un movimiento hacia afuera: la operación ecográfica deviene cartográfica y rearticula, desde una dimensión afectiva, una nueva relación entre lo íntimo y lo público, entre el presente y el pasado, y entre memoria privada y colectiva. La película nos hacen viajar por los espacios de la imaginación, los lugares de memoria y la topografía de los afectos en la que "layers of cultural memory, densities of hybrid histories, and psychogeographic transports are housed by film's spatial practice of cognition" (BRUNO, 2006, p. 22). Desafiando la oposición convencional entre afecto, discurso y razón, la afectividad se vuelve en el documental la condición de posibilidad de la subjetividad y del conocimiento. 
El otro día va hilvanando una noción de espacio a partir de la ideas y de las prácticas de pasaje. El deambular del director construye un mapa de encuentros fortuitos, una cartografía afectiva que reflexiona sobre las dimensiones y diferencias de la sociedad chilena. Pero también la "cartografía afectiva" se produce en el "adentro", en un ejercicio de contemplación que invoca huellas del pasado en el presente y, es en el corazón mismo del hogar donde se comienzan a tejer puentes con la historia colectiva. Así, junto a la expedición ciudadana, el documental de Agüero se detiene poéticamente en la precariedad y en la persistencia de un universo doméstico que nunca puede convertirse en una isla. Si, como dice Giuliana Bruno, la arquitectura es antecesora del cine (1997, p. 1) la reflexión sobre el "habitar" de Agüero funde pensamiento y sensación. La casa es un espacio experimentado que no puede ser comprendido solamente en términos geométricos, su atmósfera indefinida pero no completamente interiorizable no puede reducirse simplemente a la morfología del territorio. El trabajo de luces y sombras en el documental excede un preciosismo estético y se abre a una dimensión sensorial, afectiva y ética. La morosidad de la cámara, que se detiene en los reflejos del mundo exterior sobre la oscuridad del interior, hace de la casa una verdadera "cámara oscura" que nunca logra cerrarse al exterior porque es en la superficie misma de ese interior que se revelan espacios intermedios, de relaciones, transformaciones, traslaciones, fusiones. Unos entre-espacios de las artes como lugar de los afectos cuyos vasos comunicantes son la pintura, el arte contemporáneo, la literatura, la fotografía. De este modo, al encontrar en el afecto una forma constitutiva tanto de la experiencia estética como de la propia existencia, Agüero propone una "estética de la habitabilidad" que funde arquitectura y urbanismo, interior y exterior, presente y pasado, y expone, así, un gesto ético fundamental: sus puertas están abiertas al otro. Desde esta matriz audiovisual y afectiva, se articula una poética y una política, una forma de pensar el "cómo vivir con el otro" a partir de la práctica íntima de los espacios privados y públicos.

\section{REFERÊNCIAS}

BACHELARD, Gastón. La poética del espacio. Buenos Aires: Fondo de Cultura Económica de Argentina, 2000.

BARROS, José D'Assunção. “A cidade-cinema pós-moderna: uma análise das distopias futuristas da segunda metade do século XX”, Critica Cultural, 2011, p. 303-332.

BRUNO, Giuliana. "Projections: The Architectural Imaginary in Art”. In: Surface: Matters of Aesthetics, Materiality, and Media. Chicago, University of Chicago Press, 2014.

"Visual Studies: Four Takes on Spatial Turns." In: Journal of the Society of Architectural Historians 65 (1), 2006, p. 23-4.

Atlas of Emotion. Journeys in Art, Architecture, and Film. New York: Verso, 2002.

"Site-seeing: Architecture and the Moving Image". Wide Angle, 19.4, 1997, p. 8-24.

CERTEAU, Michele de. La invención de lo cotidiano. 1 Artes del hacer. México DF: Universidad Iberoamericana, 2000.

CRARY, Jonathan. Techniques of the Observer: On Vision and Modernity in the Nineteenth Century. Cambridge, Mass: MIT Press, 1990. 
CRESSWELL, Tim y Deborah DIXON. Eds. Engaging Film: Geographies of Mobility and Identity. Lanham, MD: Rowman \& Littlefield, 2002.

DE LOS RÍOS, Valeria. "Mapas cognitivos del Santiago del nuevo siglo. Aquí se construye de Ignacio Agüero y Play de Alicia Scherson”. Revista Chilena de Literatura, Abril/2010, p. 1-15.

DEPETRIS CHAUVIN, Irene. "Hidrarquías (Sobre "El botón de nácar", de Patricio Guzmán", Informe Escaleno, abril de 2015.

FLATLEY, Jonathan. Affective Mapping, Melancholia and the Politics of Modernism, Cambridge, Harvard UP, 2008.

FOUCAULT, Michel. “Of Other Spaces.” Diacritics, 16.1, 1986, p. 22-7.

HEIDEGGER, Martin. “Construir, habitar, pensar”. En: Conferencias y artículos. Barcelona: Ed. del Serbal, 1994.

KALE, Gül. "Interacción del cine y la arquitectura: mirando a través de la primera mitad del siglo XX", Bifurcaciones, 3, 2005. Disponeble en: http://www.bifurcaciones.cl/bifurcaciones/wpcontent/uploads/2005/06/bifurcaciones_003 Kale.pdf

KOZA, Roger. "Especies de espacios". Con los ojos abiertos. Julio de 2013. Disponible en: http://ojosabiertos.otroscines.com/transcinema-2013-01-especies-de-espacios/

LAGOS LABBÉ, Paola. “Ecografías del 'Yo': Documental autobiográfico y estrategias de (auto)representación de la subjetividad”. Comunicación y Medios, 24, 2011, p. 60-80.

MARKS, Laura. The Skin of the Film: Intercultural Cinema, Embodiment and the Senses. Durham: Duke UP, 2000.

MARTIN, Adrian. "Metamorfosis íntima: el cine y el espacio arquitectónico", Bifurcaciones, 29/10/2013. Disponible en: http:/www.bifurcaciones.cl/2013/10/metamorfosis-intima-el-cine-y-elespacio-arquitectonico/

MARÍN, Pablo. "Ignacio Agüero: "Hago cada película como si fuera la primera”. Revista Capital, 26 de julio de 2013. Disponible en: http://www.capital.cl/cultura/2013/07/26/060756-ignacio-aguero-hagocada-pelicula-como-si-fuera-la-primera

MASSEY, Doreen. For Space. Los Angeles: SAGE, 2012.

PEREC, Georges. Especies de espacios. Barcelona: Montesinos, 1999.

PÉREZ VILLALÓN, Fernando. “En el mar de la mirada”. Letras en Línea, abril de 2014. Disponible en: http://www.letrasenlinea.cl/?p=4579

RENOV, Michael. The Subject of Documentary. Minneapolis: U of Minnesota P, 2004.

SHIEL, Mark. "Cinema and the City in History and Theory". In: Cinema and the City. Oxford: Blackwell Publishers, 2001.

VIDLER, Anthony. "The Explosion of Space: Architecture and the Filmic Imaginary". Assemblage, 21, Aug/1993, p. 44-59.

\section{FILMOGRAFÍA}

Aquí se construye (o ya no existe el lugar donde nací). Dir. Ignacio Agüero. 2000.

No olvidar. Dir. Ignacio Agüero. 1982.

Como me da la gana. Dir. Ignacio Agüero. 1985.

Cien niños esperando un tren. Dir. Ignacio Agüero. 1989.

Sueños de hielo. Dir. Ignacio Agüero. 1993.

La mamá de mi abuela le contó a mi abuela. Dir. Ignacio Agüero. 2004.

El diario de Agustín. Dir. Ignacio Agüero. 2008.

El otro día. Dir. Ignacio Agüero. 2012.

Qué historia es ésta y cuál es su final. Dir. José Luis Torres Leiva. 2013. 
Recebido em14/10/2015. Aprovado em 10/11/2015.

Title: How to live together. Arts of space and affectivity in El otro dia, by Ignacio Agüero

Abstract: As dramas of mobile space, films not only exemplify topics developed by architecture and urbanism as specific fields of knowledge, but they also explore new ways of conceiving the "passages" between closed and open, visible and invisible, public and private spaces. Considering recent contributions from the field of spatial theory as well as studies on the connections between affect and space, this article discusses how the documentary El otro dia (2012), by the Chilean Ignacio Agüero, redefines the links between the modes of spatial thinking of architecture, urbanism and cinema proposing a "practice of space" that leads to an "affective mapping": a way to redefine the connections between the intimate and the public, the house and the city, biography and collective memory.

Keywords: Cinema. Chile. Spatial Thinking. Affectivity. 